\title{
"Quality quarantine": a call for less professional isolation
}

Multiprofessional teamwork is central to the work of most clinical specialties. By working together to a common purpose fragmented and inconsistent approaches to care are minimised. But these working relationships often seem to be too fragile to allow quality assurance and audit to be a multiprofessional responsibility. Perhaps fragmentation and inconsistency in quality of care are not considered to be priority issues? Or perhaps there are other reasons for the reluctance for professionals who work together to shun such affiliation when it comes to quality assurance?

The reality is that high quality care is seldom achieved by people from a single profession. In the course of getting treatment, help, and advice about even one condition a patient will encounter many different health care staff. Patients do not understand the different professional tribal associations: poor quality of care given by any one professional could tarnish the entire experience for the patient.

Strict lines of professional demarcation make no sense at all since patients cross them all the time. This is the main argument in support of the development of interprofessional audit. It is, of course, impossible to tease out the contribution of one group of professionals to satisfactory patient outcomes. Outcomes of care depend on the contributions and cooperation of several health care staff.

\section{Historical perspective}

In the mid-1980s nurses were encouraged to become involved in quality assurance as an approach to achieving and maintaining a high quality of nursing care for patients. Numerous textbooks and journal articles on the subject of "QA" were published; study days and workshops on quality assurance were held across the British Isles. Groups of nurses worked together to write standards for nursing care which could be used to assess the quality of nursing. The result was a plethora of clinical nursing standards. A few years later a similar process engaged physiotherapists, occupational therapists, speech therapists, and social workers. And in 1991 with much more noise (and money) the medical profession embarked on the process of medical audit ${ }^{12}$ and started to work out standards of medical practice which can be used to assess the quality of medical care.

The factor common to all these initiatives is that they have all developed in professional isolation.

\section{Nurses' and therapists' views}

Separate groups of nurses, physiotherapists, and occupational therapists were asked by me recently if they could explain why health care professionals, who work together in daily practice, have such an isolationist approach to quality assurance. Citing previous experience of attempts at working in multiprofessional teams, where the medical team member invariably took on the "captain's" role, they expressed concern about getting swallowed up by their "more powerful" medical colleagues. They predicted that when they become confident in auditing within their own professional groups then they will be able (and perhaps willing) to become involved in interdisciplinary audit.

\section{Doctors' views}

One dictionary's definition of quarantine reads: "isolation for medical reasons." Conversations with medical colleagues have led me to believe that medical audit is a form of "quality quarantine." The reluctance expressed by some doctors to involve "outside disciplines" is justified by them on the basis of professional independence, confidentiality, and the dangers of litigation. Such comments support the Audit Commission's finding that medical audits were often held "in camera."

\section{Dismantling the barriers of professional isolation} Nurses work in isolation to obtain confidence and doctors to retain independence. How long will this unnecessary duplication continue? How can patient care be genuinely improved with such a piecemeal approach to quality assurance? A situation where uniprofessional control is perceived as more important than interprofessional communication may not only minimise the impact of audit programmes but also result in a poorer quality service.

Different professionals who base their practice on different models of care may also differ in their interpretation of what constitutes a quality problem. ${ }^{4}$ The argument is not about which approach is right, or more important, or carries more weight; the real issue is that members of different health care professions who work together need to develop a greater understanding and respect for each other's contributions both to care and to the quality of care. The aim must be to set shared objectives which are patient centred and not profession centred.

Professional isolation begins during training. There is no common curriculum for the different students of health care. Sharing even a small part of the introductory curriculum to clinical studies might help towards fostering understanding of the roles and contributions of other professions and help to promote the philosophy that no single profession holds a monopoly on health problems or on patient care.

The division of duplication of labour is demonstrated by the different patient records compiled for each patient admitted to hospital. A common patient record used by all those contributing to a patient's care would be a step towards reducing professional isolation and would make interprofessional quality assurance easier.

A programme of quality assurance which genuinely seeks to improve the quality of care and to provide a service more responsive to patients' needs may disturb traditional patterns of influence and power. Influence has been shifting between managers and practitioners, between practitioners and patients, and also between different professional groups. Any change in the distribution of power or influence is difficult both for those that seem to lose it and also for those who have to take on a new autonomy and responsibility. By working towards a patient focused approach to care such changes will be easier to understand and to bear.

The number of examples of successful clinical audits is increasing. None the less, there is still much work needed to develop and evaluate multiprofessional 
approaches to quality assurance. Managers may need to take the lead to encourage such work, ${ }^{3}$ but it is the different professional groups which will need to examine working practices. Anything less will result in missed opportunities to improve patient care.

There is one caution I want to express about taking a multiprofessional approach to quality assurance. The aim is not to hide or to annull the different approaches of the various professions to patient care but rather to share the different perspectives. Within such a strategy we must avoid acquiring tunnel vision about methods of audit or quality assurance. Different jobs require different tools. Similarly, depending on the focus of the investigation, auditors may use different approaches to data collection, ${ }^{4}$ and a healthy regard for both quantitative and qualitative methods of audit should be encouraged and maintained.

HUGH MCKENNA

Lecturer

Department of Nursing

Faculty of Social and Health Sciences,

University of Ulster

Coleraine,

County Londonderry. BT52 ISA

1 Secretaries of State for Health, Wales, Scotland, and Northern Ireland. Working for patients. London: HMSO, 1989. (Cmnd 555. )

2 Secretaries of State for Health, Social Security, Wales, and Scotland. Caring for people, community care in the next decade and bevond. London: HMSO, 1989. (Cm 849.)

3 Audit Commission. The virtue of patients: making best use of ward resources. London. HMSO, 1991.

4 Kitson AL. Playing by the rules.... Quality in Health Care $1992 ; 1: 149-50$ 